Artigo Original

Atenção à Saúde

\title{
COMPETÊNCIAS DE ENFERMAGEM PARA A PREVENÇÃO DE NECROSE E RETRAÇÃO EM QUEIMADURAS
}

NURSING SKILLS FOR THE PREVENTION OF NECROSIS AND RETRACTION IN BURNS

Amanda de Barros Schardosim1, Maria Aparecida de Oliveira2, Karina Cardoso Gulbis Zimmermann3, Mágada Tessmann3 , Luciana Rosa4, Maria Teresa Brasil Zanini5

1Especialista em Estomaterapia.

2Acadêmica de Enfermagem Unesc.

3Doutora em Ciências da Saúde. Estomaterapeuta. Docente Enfermagem, Medicina Unesc.

3 Doutora em Ciências da Saúde. Estomaterapeuta. Docente Enfermagem, Medicina e Odontologia Unesc.

4 Mestre em Ciências da Saúde.

5Especialista. Docente Enfermagem Unesc.

Endereço para correspondência: *Karina Carodos Gulbis Zimmermann Av.Universitaria, 1001. Bairro Universitário. CEP 88880000 - Criciúma, Brasil. Email: karina@unesc.net 


\section{RESUMO}

O presente estudo teve como objetivo identificar as competências de enfermagem voltadas para a prevenção de necrose e retração em queimaduras, em uma unidade de queimados. Tratou-se de uma pesquisa de abordagem metodológica qualitativa, descritiva-exploratória e de campo, realizada com quinze profissionais, sendo 02 (dois) enfermeiros e 13 (treze) técnicos de Enfermagem da Unidade de Queimados de um hospital do Rio Grande do Sul. Os dados foram analisados por meio da técnica de categorização proposta por Minayo, com a qual foi possível elencar as principais idéias do grupo sobre o tema pesquisado. As principais categorias percebidas e analisadas que chamaram a atenção foram relacionadas ao cuidado com a infecção e o tratamento da ferida local, no intuito de consagrar como uma das estratégias para prevenção de necrose. Na retração por sua vez, as competências para prevenção mais elencadas foram o posicionamento do paciente, curativo com técnica correta e utilização de suportes na área lesionada. Todavia, vale destacar que a dor foi apontada como a principal dificuldade na realização das intervenções, inclusive de mobilizações e reposicionamentos devido à resistência ao toque, contribuindo assim ao possível aparecimento de complicações como a retração ou cicatrização ineficaz. Quanto ao aperfeiçoamento, verifica-se que há necessidade de abordar e implementar um pouco mais a temática voltando-se para a SAE e as competências de Enfermagem nesse cuidado, uma vez que observou-se que as questões administrativas preenchem a maior parte do tempo dos enfermeiros. $O$ aperfeiçoamento de condutas e formação de mais serviços especializados nesta área, além de auxiliar os profissionais de enfermagem no cuidado destes pacientes de forma a contribuir para a promoção da reabilitação social e funcional dos mesmos, objetivará a minimização de complicações como necrose e retração.

Descritores: Queimaduras. Enfermagem. Prevenção. Necrose. Retração.

\section{ABSTRACT}

The present study aims to identify the nursing skills focusing on the prevention of burning necrosis and retraction in a burn unit. The study has been a qualitative, 
descriptive and exploratory field methodological approach. The survey was conducted with fifteen professionals; two nurses and thirteen nursing technicians of a hospital burn unit in the state of Rio Grande do Sul - Brazil. The data were analyzed through a categorization technique proposed by Minayo. The care of the infection and the treatment of the wound site, were the main categories in the realm of the study pointing out the strategies to prevent necrosis. In the retraction, the skills listed for prevention were patient positioning, bandaging with correct technique and use of physical holding in the injured area. The pain was cited as the main difficulty in carrying out interventions, due touch tenderness, thus contributing to the possible onset of complications, such as inadequate healing and undesirable retraction. Objecting the better outcomes in this area of nursing care, it has been demonstrated in the survey the need to reorganize the issue of the Nursing Care Systematization (NCS) - and the nursing function in this area to minimize the time used in administration matters which seems to waste most of the nursing time. The improvement of the conducts and training of more specialized services in this area, as well as to assist nursing professionals in the care of these patients in order to contribute to the promotion of social and functional rehabilitation, will aim to minimize complications such as necrosis and retraction.

Descriptors: Burns. Nursing. Prevention. Necrosis. Retraction.

\section{INTRODUÇÃO}

As queimaduras constituem um dos maiores traumas que uma pessoa pode ser exposta, pois ela deixa sequelas físicas, psíquicas e emocionais para toda a vida. Resultam em lesões significativas, com complicações das quais exigem tratamento global, focado na prevenção em longo prazo de problemas como cicatrizes, contraturas e outros que limitam a função física1.

Apesar de toda a tecnologia vigente, os resultados do tratamento para queimaduras graves, sejam elas provocadas por chamas, eletricidade ou produtos químicos, continuam muito limitados. É necessário investir-se em capacitações e cursos de normatizações ao atendimento a queimados. Outra parte fundamental é o apoio do poder público em criar novas unidades de referência para tratamento de queimaduras, com atendimento de alta complexidade oferecido pelo SUS. O 
tratamento e suporte especializado para as sequelas ocasionadas pelas queimaduras é outro tema que precisa ser revisado

Nessa pesquisa serão abordadas as competências de enfermagem para a prevenção de retração e necrose, uma vez que essas duas complicações podem ser evitadas a partir de um planejamento humanizado e cuidadoso por parte das equipes. Retração ou cicatriz retrátil é aquela que se apresenta tensa e repuxando, causando contratura entre áreas corporais envolvidas. Geralmente resulta de um ferimento que provoca a perda de um segmento de pele, podendo assim formar uma cicatriz que traciona suas margens, impedindo o movimento normal de articulações ${ }^{3}$.

A prioridade inicial consiste em evitar complicações relacionadas à imobilidade. A mudança de decúbito e o posicionamento adequado são práticas de enfermagem essenciais que impedem as contraturas. Exercícios de amplitude de movimentos passivos e ativos devem ser iniciados desde o primeiro dia da admissão e continuam depois do enxerto, conforme limitações prescritas. A enfermagem deve ainda monitorar as áreas imobilizadas para detectar sinais de insuficiência vascular e compressão nervosa4 (SMELTZER, et al, 2009). A presença de tecido necrótico em uma ferida por queimadura representa um agravante no processo de reparação tecidual, pois retarda 0 processo de cicatrização, sendo a realização de desbridamento essencial para o tratamento desta lesão5 .

Sua prevenção consiste em evitar a infecção da ferida da queimadura, através de frequente avaliação microbiológica da ferida, pois a pele destruída favorece a invasão bacteriana. A infecção da área queimada pode ser a principal complicação nas pessoas queimadas, os sinais de infecção da ferida incluem: coloração enegrecida da área queimada, evolução de uma necrose parcial para uma necrose total, coloração esverdeada do tecido subcutâneo, aparecimento de vesículas em lesões cicatrizadas, descolamento rápido do tecido necrótico e aparecimento de sinais flogísticos6. Os processos de recomposição epidérmica e a própria capacidade do organismo reconstruir-se podem ser alcançados com maior rapidez por meio de cuidados como: desbridamento, limpeza e higiene local7 .

A lesão por queimadura, quando não tratada precocemente e da forma correta, poderá acarretar deformidades, mutilações e alterações estéticas grosseiras que poderão ter notória repercussão no desenvolvimento futuro da pessoa 
queimada, comprometendo, inclusive, sua relação biopsicossocial. Dessa forma, a intervenção precoce melhora a qualidade de vida e estimula a formação de identidade sólida, com menor comprometimento da integridade psicofuncional dessas pessoas8 .

A assistência de enfermagem requer uma formação científica especializada, pois o cuidado clínico de enfermagem é abrangente, estendendo-se do estágio clínico agudo até a fase de reabilitação. A prevenção das deformidades está relacionada com a prática precoce e persistente do posicionamento adequado em cada segmento corporal, sendo imprescindível à colaboração de toda a equipe e principalmente do paciente7. A equipe de enfermagem envolvida com queimaduras precisa ter conhecimento em relação às novidades disponíveis no mercado, que representam avanço tecnológico, e estar constantemente capacitada, com intuito em reduzir a taxa de mortalidade e também complicações como: sequelas físicas e patológicas. O enfermeiro também deve ser capaz de comunicar-se efetivamente com os pacientes, familiares e equipe 7 .

Deve-se promover a capacitação de seus profissionais antes do início das atividades e de forma permanente, em conformidade com as atividades desenvolvidas 9 . O processo de enfermagem é parte fundamental no tratamento integral ao paciente queimado. Amparado na resolução 358/2009 do COFEN, este deve ser realizado, de modo deliberado e sistemático, em todos os ambientes, públicos ou privados, em que ocorre o cuidado profissional de Enfermagem. Organiza-se em cinco etapas: Coleta de dados de Enfermagem (ou Histórico de Enfermagem), Diagnóstico de Enfermagem, Planejamento de Enfermagem, Implementação e Avaliação de Enfermagem10 .

A prestação de cuidados de enfermagem é essencial na recuperação e reabilitação do paciente, contudo, o enfermeiro é o responsável direto pela organização sistematizada da atenção prestada a pessoa queimada11. Este estudo objetivou identificar quais as competências de enfermagem voltadas para a prevenção de necrose e retração em queimaduras, em uma unidade de queimados do estado do Rio Grande do Sul.

\section{MÉTODOS}

Revista Inova Saúde, Criciúma, vol. 7, n. 1, jul. 2018.

ISSN 2317-2460 
Trata-se de uma pesquisa de abordagem qualitativa do tipo exploratória descritiva e de campo, uma vez que foram identificadas, analisadas e descritas as competências de enfermagem na prevenção de necrose e retração em queimaduras em um cenário de prática dos profissionais demonstrando seus conceitos e representação do tema em seu cotidiano. O Projeto de Trabalho de Conclusão de Curso - TCC foi encaminhado ao Comitê de Ética em Pesquisa da UNESC e posteriormente ao comitê da instituição hospitalar que rege a Unidade de Queimados. Após a aprovação da pesquisa pelo Comitê de Ética em Pesquisa da UNESC (CAAE: 30198914.0.0000.0119) e liberação do Comitê de Ética em Pesquisa da instituição hospitalar/unidades de queimados do estado do Rio Grande do Sul; iniciou-se a coleta de dados com quinze (15) profissionais após a assinatura do Termo de Consentimento livre e Esclarecido.

A coleta de dados foi efetuada por meio de entrevista semiestruturada, com questões abertas aplicadas pelos próprios pesquisadores no contexto do estudo, previamente agendadas junto à instituição e precedidas de assinatura do TCLE. Além disso, foi realizada a observação sistemática da assistência de enfermagem à pessoa queimada. Os princípios éticos foram respeitados, protegendo os direitos dos envolvidos na pesquisa, em atenção às determinações das Diretrizes e Normas Regulamentadoras de Pesquisas Envolvendo Seres Humanos, estabelecidas pela Resolução 466/2012 do Conselho Nacional de Saúde.

As categorias são empregadas para estabelecer classificações, significa agrupar elementos, ideias ou expressões em torno de um conceito capaz de abranger tudo que pode ser utilizado em qualquer tipo de análise em pesquisa qualitativa12. O processo ocorre em fases, a saber: Pré-análise - onde se devem organizar todos os dados, são necessários que se leia todo o material, a fim de determinar alguns critérios e analisar e registrar impressões do dado; Exploração do material - é a fase da categorização, onde os dados brutos do material são codificados para se alcançar o núcleo de compreensão do texto. Foi preciso uma leitura minuciosa de todo o material e releituras para elencar as categorias. Tratamento dos resultados obtidos e interpretação - neste momento partes e do princípio quantitativo, em que se deve tentar desvendar o conteúdo que está por trás do manifestado. 


\section{RESULTADOS}

No decorrer da pesquisa da instituição hospitalar na Unidade de queimados, foi possível estabelecer algumas características da equipe de Enfermagem. $\mathrm{O}$ ato de cuidar se volta para a feminilidade, uma vez que é visto como uma ação pautada nas "qualidades naturais" das mulheres13. O que pode se dizer caso observada a história e nascimento da profissão.

A idade dos profissionais variou de 36 a 57 anos, e na escolaridade 03 (três) profissionais possuem superior completo, 04 (quatro) possuem superior incompleto, e 08 (oito) ensino médio profissionalizante. O tempo de serviço mostra que a unidade não apresenta problemas de rotatividade, visto que a maioria dos profissionais está há mais de 07 (sete) anos no setor.

Atribui-se a esse resultado a pré-disposição para trabalhar com queimados, é preciso saber administrar importantes estressores, como dor permanente e sofrimento. Evidenciou-se que os profissionais atuantes em unidades de queimados necessitam ter consciência que estarão lidando com ocasiões dolorosas e subjetivas. Mas mesmo sabendo, o profissional envolve-se, e isto poderá desenvolver experiências estressantes relacionadas à dor. A falta de conhecimento não é o único obstáculo para o tratamento doloroso, existe a dor, que por si só já é complexa; exigindo além do conhecimento, a capacidade do profissional de manter uma visão holística sobre o ser cuidado14 .

Para que um profissional seja capaz de prestar cuidados em uma unidade de queimados dentre outras coisas, é necessário o investimento de cunho técnicocientífico, pois uma equipe qualificada é de suma importância na minimização dos agravos provocados pela queimadura13.

- Categoria 1 - formação continuada

A educação continuada é definida como um conjunto de atividades educativas para atualização do indivíduo, onde é oportunizado o desenvolvimento do funcionário assim como sua participação eficaz no dia a dia da instituição9. Dentre as respostas, verifica-se que os enfermeiros pesquisados tiveram capacitação quando foram contratados, todavia, entre os técnicos essa realidade se mostrou de 
forma diferente, o que delimitou no decorrer do trabalho a falta de preparo para lidar com situações intrínsecas, a atenção voltada ao cuidado de pessoas com queimaduras, bem como, o desgaste profissional, uma vez que se trata de uma área em que a dor e mudanças físicas e psíquicas parecem ser evidentes.

O aprendizado foi diário e muito traumatizante, fui colocada na unidade sem ter noção do que era. (TE1).

\section{- Categoria 2 - Treinamentos e capacitações}

No decorrer do processo de trabalho a equipe menciona que recebe treinamentos institucionais ou empresas de curativos, capacitações proferidas pelo médico (E1, TE9, TE11), ou pelo Enfermeiro (TE1, TE5, TE6, TE7, TE8, TE10, TE13). Referem que quando os enfermeiros e médicos retornam de congressos, repassam o que aprenderam para a equipe relacionando relacionado às situações de queimaduras, porém, a capacitação institucional é geral para cuidados com feridas ou temas previamente selecionados em forma de palestras.

A pessoa queimada, devido a sua complexidade, necessita de cuidado diferenciado, de um profissional enfermeiro com competência em três elementos fundamentais: saber (conhecimento científico), fazer (capacitação técnica) e valores (pessoais e profissionais). Diga-se que competência de maior complexidade, é devidamente fundamentada na Lei do exercício profissional o 7.498/86, que diz que ao enfermeiro cabe-lhe cuidados diretos de enfermagem a pacientes graves com risco de vida, cuidados estes de maior complexidade técnica e que exigem conhecimentos de base científica e capacidade de tomar decisões imediatas 15 .

- Categoria 3 - Sistematização da Assistência de Enfermagem (SAE)

Para desenvolver a SAE, o Conselho Federal de Enfermagem, coloca que o processo de enfermagem é um instrumento que documenta a prática profissional e evidencia a contribuição da Enfermagem na atenção à saúde da população10. Além disso, sistematização da assistência de enfermagem é um dos meios que o enfermeiro dispõe para caracterizar sua prática profissional e aplicar seus conhecimentos técnicos, científicos e humanos na prestação de assistência ao paciente. Trata-se ainda da real definição do seu papel15 . O planejamento de 
enfermagem no serviço de queimaduras organiza o cuidado que deve ser prestado ao paciente assistido, mas, quando perguntado aos profissionais sobre a existência de SAE, observa-se que estes demonstram não saber seu significado, e só responde a questão após explicação das pesquisadoras.

Os profissionais manifestaram que ela existe por meio de manuais de normas e rotinas da unidade, exceto TE1, TE3, TE10, TE12 que mencionam que os profissionais seguem a prescrição médica, sendo as condutas decididas por eles. Neste sentido pesquisas realizadas pelo Conselho Regional de Enfermagem de São Paulo (2005), revelam que $65 \%$ das instituições não souberam como implantar a SAE, 38\% estavam em fase de implantação, em 15\% houve relutância e/ou impedimento dos profissionais de saúde e em 10\% houve impedimento por parte da instituição16.

- Categoria 4 - Competência do Enfermeiro

Observa-se nos depoimentos que a realização das atividades do dia a dia é compreendida como atividades práticas, enquanto que 0 processo de enfermagem, considerado como uma ação de registrar, como uma atividade teórica. Nas falas os técnicos associam a SAE como uma responsabilidade do enfermeiro.

Desconheço. A enfermeira que faz essa parte. (TE1).

Não sei. O que faço é escutar os relatos do paciente e passar para a enfermeira. (TE3).

É realizado somente pelos enfermeiros. Eles avaliam o paciente e intervém conforme a sua necessidade. (TE5, TE9).

Nunca ouvi falar na SAE. Ao ser esclarecido sobre o tema]. São as enfermeiras que realizam e considera muito importante. (TE6, TE8).

Não realizo. A enfermeira também não faz, porque é responsável por dois setores e vai ao setor para atender intercorrências. (TE10).

- Categoria 5 - Processo de Enfermagem na prevenção de complicações

A assistência de enfermagem está presente em todo processo de vida do indivíduo, de forma preventiva ou assistencial, orientada por manuais, protocolos ou até mesmo pela própria forma de trabalhar. É essencial na recuperação e reabilitação do paciente, além de minimizar as possíveis sequelas que o mesmo possa adquirir. $\mathrm{O}$ cuidado com a pessoa queimada está cada dia mais completo 
devido aos avanços no conhecimento da fisiopatologia e ao surgimento de novas possibilidades de tratamento, conduzindo assim a uma maior sobrevida no grupo de pacientes que até um tempo atrás iriam a óbito. Estes são resultados do trabalho em equipe, pois dentro deste grupo de profissionais, está a enfermagem17 .

O diagnóstico de enfermagem possibilita a comunicação da prática e das perspectivas dos cuidados, objetivando agilizar, padronizar e efetivar a prática da sistematização da assistência de enfermagem, características essenciais na assistência de queimados. Adequam bases para sugerir metas e intervenções de enfermagem visando obter resultados esperados como encargo do enfermeiro7 . Na realização da entrevista e na fase de observação, constata-se que os enfermeiros não realizam diagnósticos de enfermagem, mas realizam intervenções a todo o momento, e essas informações perdem-se, pois não são registradas, conforme fala apresentada abaixo. Não tem instrumento pronto. Mas a avaliação do paciente é feita.

Não trabalhamos com diagnósticos de enfermagem (E2).

Conheço a SAE e não realizo. Não sei qual instrumento (TE11).

- Categoria 6 - dor, posicionamento e risco de retração

A equipe de enfermagem tem um importante papel na avaliação e alívio ou amenização da dor da pessoa queimada. Além disso, pode lançar mão de seus conhecimentos e das possibilidades terapêuticas existentes. Pode se dizer que a equipe de enfermagem é quem lida diretamente e presencia a verbalização da dor, uma vez que realizam os cuidados nas 24 horas. Geralmente o período de maior elevação de dor é quando as pessoas queimadas precisam ser mobilizadas no leito ou quando recebem o banho e os curativos, o que faz com que recusem a realização de procedimentos, ocasionando assim possíveis complicações como, por exemplo, a retração.

[...] ele (paciente) não colabora com o serviço; (E1).

[...] dificuldade de realizar os procedimentos; limitação do paciente; (E2).

A resistência do paciente ocasionada pela dor. Não querer ser tocado. (TE13)

Verifica-se que o paciente apresenta limitações relacionadas à dor, e a equipe relata ainda embora se tenha resistência da pessoa, após a mobilização o 
posicionamento correto do paciente (TE2, AE2, TE4, TE6) e as medidas de conforto (AE2, TE3, TE4, TE6, TE8) são condutas que auxiliam no alívio da dor. O posicionamento no leito tem como objetivos, a diminuição de edema, o alinhamento de segmentos, cicatrização em elasticidade cutânea máxima e prevenção de zonas de pressão e retração18 .

Durante o período de observação presenciou-se vária intervenções como tentativa de minimizar a ocorrência de complicações relacionadas à retração cicatricial. Mesmo esta não sendo diretamente uma das complicações mais lembradas pelos profissionais, é um agravante na recuperação e reabilitação do paciente. Ao citar "manejo correto" ou "posicionamento", já se está diminuindo o risco de retração, visto que representam uma das formas de prevenção.

- Categoria 7 - Necrose: uma raridade

As queimaduras podem ser consideradas contaminadas pela ocorrência três grandes fatores: sujidades do local de ocorrência da injúria, presença de colonização imediata por micro-organismos e pela rápida proliferação em decorrência da grande quantidade de tecido desvitalizado5. Os sinais locais de infecção da ferida incluem: coloração enegrecida da área queimada, evolução de uma necrose parcial para uma necrose total, coloração esverdeada do tecido subcutâneo, aparecimento de vesículas em lesões cicatrizadas, descolamento rápido do tecido necrótico e aparecimento de sinais flogísticos (hiperemia e edema) em áreas próximas às queimaduras 19 .

$\mathrm{O}$ cuidado das feridas provocadas pela queimadura tem o objetivo de cicatrização em tempo oportuno, com mínimas complicações. Neste sentido, a presença de tecido necrótico no leito da ferida, interfere na reparação tecidual, diante isso o desbridamento reduz a quantidade de tecido necrótico e, consequentemente, a contaminação da ferida, favorecendo o crescimento do tecido de granulação5. No questionamento sobre quais as condutas para evitar necrose em pessoas queimadas, todos os profissionais relataram não ter paciente com necrose na unidade ou ser algo raro, todavia, recebem pacientes transferidos de outros locais, que por vezes chegam com essa complicação, a qual imediatamente é tratada. 
Nossos pacientes raramente desenvolvem necrose, mas muitos pacientes chegam a unidade com capa necrótica, pois estavam sendo tratados em ambulatórios. (E1)

Uma das complicações é falta de atendimento inicial adequado (paciente que chega com ferida necrosada), estava fazendo tratamento em casa ou outra instituição. (E1) $O$ atendimento inicial não adequado faz com que ele chegue à unidade e vá direto para isolamento (devido infecção e necrose). (TE1)

Necrose acontece em pacientes que vem de outros lugares ou que estão se tratando em casa. (TE7)

Alguns hospitais de algumas cidades não oferecem tratamento adequado ao paciente queimado e nem profissionais que saibam prestar o primeiro atendimento. Quando isso acontece, chegam pacientes aqui com capas de necrose. (TE5)

Mediante essas afirmações perguntou-se como tratar e prevenir o aparecimento de necrose:

Realizar a remoção da necrose no primeiro momento se possível ou no $2^{\circ}$ momento no bloco cirúrgico. (E2)

O tratamento é remoção da necrose, realizada por desbridamento. (TE11)

Entende-se com as falas apresentadas, que apesar dos profissionais alegarem a inexistência de necrose na unidade, indiretamente ela está presente, ora na admissão do paciente, ora na realização de procedimentos em escaras de pacientes mais graves que estão na UTI. O fato é que os profissionais falam da necrose como um fator externo a unidade. Como forma de tratamento respondem que é a realização de desbridamento e a prevenção é realizada com controle de infecção. Lesões com extensas e profundas placas necróticas devem ser considerado o desbridamento cirúrgico, complementado pelo desbridamento químico através de pomadas ou curativos especiais. Afirmação esta que fundamenta a mesma forma de atuação na unidade de queimados em estudo20 . Nos períodos da observação sistemática, nos pacientes internados não visualizamos presença de necrose tecidual e não presenciamos a admissão de pacientes, visto como um fator atenuante na ocorrência de necrose. Durante os procedimentos em bloco cirúrgico, também não houve desbridamentos, ocorreram apenas enxertias.

- Categoria 8 - Resistência e baixa adesão no posicionamento

Retração Queimaduras profundas lesam a derme, sua regeneração é lenta e a cicatriz é vultosa. Esta área lesionada tende a contrair, desfigurando a pele 
e danificando o seu funcionamento7 . Conforme a observação sistemática percebese que na prevenção de retração, a enfermagem é responsável por realizar curativos adequadamente, reposicionar o paciente a cada duas horas, providenciar suportes (braçadeiras, telas, espumas) para posicionamento do membro lesado, estimular a independência e reabilitação da pessoa queimada, dar continuidade ao trabalho do fisioterapeuta e da terapeuta ocupacional e realizar orientações de alta hospitalar.

O processo de trabalho conjunto é essencial, para evitar retrações e deformidades como vemos na figura 01. A retração foi citada pelos profissionais como uma das complicações a pessoa queimada no período posterior a fase aguda. [...] falta de adesão dos pacientes na continuidade do tratamento após alta hospitalar. Porque não gostam de usar a malha e não usam. (TE2)

[...] Depois da fase aguda a principal complicação é a retração. (TE6)

[...] é preciso ter manuseio correto para não prejudicar seu quadro (cicatrização e retração) (TE8).

A resistência do paciente ocasionada pela dor. Não querer ser tocado. (TE13)

Um dos aspectos mencionado foi a baixa adesão do paciente para 0 reposicionamento, em virtude, justamente da dor sentida e referida ao mobilizar-se. Todavia, vimos no decorrer da pesquisa que a equipe realiza o manejo da dor e também insiste para que esses façam as movimentações. Como conduta para evitar retração foi citado:

[...] posicionamento do paciente. (TE3)

[...] Orientar sobre o posicionamento do paciente no leito a prevenir retração. Prevenção de retração através de orientação do posicionamento e continuidade ambulatorial do tratamento após alta hospitalar. (E2)

[...] Começar a trabalhar a retração desde a entrada do paciente na unidade. (E1) [...] A retração precisa ser trabalhada no momento da internação até o período em casa. (TE1).

[...] Orientar a importância do tratamento pós-alta hospitalar para prevenir retrações. (TE2)

Os pacientes precisam de um acompanhamento maior no período que voltam para casa. A grande maioria retorna ao hospital devido às retrações. (TE6)

A retração é um cuidado em equipe e também deve ser continuado externamente. (TE10)

De acordo com as falas apresentadas, os profissionais demonstraram preocupação com as retrações no período de alta hospitalar. Relatam que o 
paciente quando ganha alta pensa que está curado e não se atem nas orientações fornecidas. Manifestam profundo pesar e receber novamente pessoas que retornam para tratamento de retrações. Foi o caso de uma criança de 2 (dois) anos que havia tratado queimadura nas mãos, ficou internada, fez o tratamento, mas não teve continuidade em casa. Retornou ao setor com as duas mãos fechadas devido à retração. No período próximo à alta hospitalar, o paciente pode apresentar, também, além de limitações físicas e psicológicas, limitações emocionais e/ou sociais. Muitas vezes, os membros da família recusam-se a dar continuidade ao tratamento, sendo que o cuidado familiar e de importante ajuda nessa fase pós-traumática para redução do impacto das queimaduras7 .

Quando recebem alta, as pessoas queimadas são assistidas no ambulatório do hospital e devem comparecer conforme agendamento, porém, muitos destes não fazem o retorno para o tratamento, deixando até de usar as malhas, parte fundamental da minimização de cicatrizes. Salienta-se ainda que apesar de ter sido citada como uma complicação relacionada à falta de adesão e posicionamento inadequado, a retração também pode ocorrer por imobilizações inadequadas, falta enxertia precoce.

- Categoria 9 - prevenção de necrose e retração

$\mathrm{Na}$ finalização da entrevista foi questionado sobre a importância do tema retração e necrose na assistência a queimados. Todos os profissionais acharam de grande relevância a pesquisa realizada.

É importante a abertura de mais unidades de tratamento e profissionais capacitados para esse tipo de acontecimento. (TE1)

O tema é muito importante, pois alguns hospitais de algumas cidades não oferecem tratamento adequado ao paciente queimado e nem profissionais que saibam prestar o primeiro atendimento. (TE5)

O trabalho é muito importante. Sugiro que o trabalho do enfermeiro vá além do período de internação. Os pacientes precisam de um acompanhamento maior no período que voltam para casa. (TE6)

As escolas de formação devem inserir em suas disciplinas conteúdos que contemplem assuntos sobre a assistência de enfermagem a vítimas queimadas, principalmente por ser uma assistência de alta complexidade. A abordagem incorreta desse a pessoa queimada poderá ser traumatizante, pois um procedimento Revista Inova Saúde, Criciúma, vol. 7, n. 1, jul. 2018. 
errado irá causar dor ao paciente, além da própria aflição originada das queimaduras7 .

Todos os cuidados estabelecidos têm por finalidade diminuir os riscos de complicações e sequelas, ajudando na melhora do doente. Além disso, foi possível compreender a necessidade de assistência adequada, contínua e interdisciplinar podendo contribuir efetivamente no processo de cura e reabilitação do paciente. Vários profissionais precisam trabalhar juntos para a retração: enfermagem, fisioterapia, terapeuta ocupacional. (TE8)

Percebe-se ainda a necessidade por parte dos profissionais que o serviço em queimaduras seja amplamente divulgado e melhor trabalhado. Aponta-se ainda a importância de políticas públicas voltadas à prevenção, pois a maior parte das queimaduras pode ser evitada. É sempre bom as pessoas aprenderem, para aumentar o conhecimento e atender melhor os pacientes.

Aprender também para passar para outras pessoas. (TE3)

As pessoas precisam aprender que queimadura pode ser prevenida sim. (TE6).

\section{DISCUSSÃO}

Percebeu-se com o estudo desenvolvido que a equipe de enfermagem é quem está ligada diretamente ao cuidado a pessoa queimada. A retração e a necrose são consideradas de grande relevância no tratamento e que necessitam de cuidado contínuo. O pensamento crítico, decisão clínica e identificação das necessidades do paciente, são requisitos que o enfermeiro atuante em uma unidade de queimados deve possuir. Para garantir essas atribuições e melhorar embasamento teórico e prático da assistência de enfermagem a pessoa queimada, fazem-se necessárias atualizações específicas de conteúdos que remetem diretamente aos cuidados deste paciente21.

O cuidado com a infecção e o tratamento da ferida local foram citados pelos participantes como estratégias para prevenção de necrose sendo relatada ainda a ausência de desenvolvimento deste quadro na unidade, os casos de necrose geralmente são na admissão do paciente, indo diretamente para desbridamento. Nas queimaduras profundas, há uma quantidade significativa de tecidos necróticos, o que facilita o desenvolvimento de infecção, pois esses tecidos 
fornecem nutrientes para as bactérias que necessitam de pouco oxigênio para sobreviver, consumindo-o e diminuindo ainda mais a quantidade de oxigênio disponível para os tecidos, sendo esses por consequência desvitalizados19 . Na retração as competências para prevenção mais elencadas foram o posicionamento do paciente, curativo com técnica correta e utilização de suportes na área afetada.

Demonstrou-se ainda profundo interesse da equipe para 0 atendimento das pessoas queimadas no período pós-hospitalar. Visto que um grande número destes deixa de usar as malhas, fazer os exercícios e comparecer ao ambulatório para dar continuidade ao tratamento. Na prevenção de retração, a equipe tem como prioridade inicial evitar complicações da imobilidade, realizando o posicionamento adequado do paciente, auxiliando nos exercícios e promovendo a independência relacionada ao seu autocuidado7. A dor foi apontada como a principal dificuldade na realização das intervenções, devido à resistência ao toque, contribuindo assim ao possível aparecimento de complicações.

\section{CONCLUSÕES}

Este estudo apresentou as competências de enfermagem na prevenção de necrose e retração em queimaduras. A análise temática das falas permitiu a criação das categorias: Formação continuada, Treinamentos e capacitações, SAE, Competência do enfermeiro, Processo de enfermagem na prevenção de complicações, Necrose: uma raridade, Resistência e baixa adesão no posicionamento: retração e Prevenção de necrose e retração. Frente aos resultados, notou-se o déficit de atuação dos enfermeiros na realização de atividades privativas dele, como por exemplo, o desenvolvimento da sistematização da assistência de enfermagem em sua totalidade. $O$ diagnóstico de enfermagem na pessoa queimada objetiva a correta estratégia terapêutica e a elaboração de um plano de cuidados efetivo, e que deixa de ser realizado na unidade. Considera-se que o estudo realizado alcançou os objetivos propostos, visto que identificou as principais competências realizadas pela equipe de enfermagem para a prevenção de necrose e retração na pessoa queimada. Contribui ainda para a melhor compreensão do tratamento da pessoa queimada e a importância de uma equipe capacitada. 
Elegeu-se como dificuldade no desenvolvimento do estudo, a carência de publicações sobre competências de enfermagem voltadas para a prevenção de complicações a pessoas queimadas. As vivências compartilhadas com a equipe de enfermagem estudada foram importantes durante a busca de novos conhecimentos em relação à queimadura. A confiança adquirida permitiu a conquista de espaço para a realização das atividades propostas. Compreendeu-se assim, que para estabelecer uma relação benéfica entre uma equipe profissional, são necessários respeito e limites individuais. Concluiu-se este estudo com satisfação, dentre os vários aprendizados, ficará marcado a lembrança de momentos que mostraram o quanto são pequenos alguns sofrimentos frente à realidade apresentada pelos pacientes e profissionais que trabalham nesta área.

\section{REFERÊNCIAS}

1. Meyer CM, köche FE, Souza MEP, Leonardi DF. Sequelas de queimaduras: retração cervical. Rev Bras Queimaduras. 2012:11(1):38-42. Disponível em http://rbqueimaduras.org.br. Acesso em 25 de outubro de 2013.

2. SBQ - Sociedade Brasileira de Queimaduras. Dia de luta contra as queimaduras. 2012. Disponível em http://sbqueimaduras.org.br/dia-de-luta-contra-asqueimaduras/. Acesso em 25 de outubro de 2013.

3. Zamarian Jr W. Cirurgia Reparadora. Cirurgia Plástica Londrina. 2013. Disponível em: http://www.cirurgiaplasticalondrina.com.br/corpo/cirurgia-reparadora/. Acesso em 05 de fevereiro de 2014.

4. Smeltzer SC, Bare BG, Hinkle JL, Cheever KH. Brunner \& Suddarth. Tratado de enfermagem médico-cirúrgica - 11aㅡ edição. Rio de Janeiro: Guanabara Koogan;2009. 642p.

5. Rossi LA, Menezes MAJ, Gonçalves N, Ciofi-silva CL, Farina-Jr JÁ, Stuchi RAG. Cuidados locais com as feridas das queimaduras. Rev Bras Queimaduras. 2010; 9(2): 54-59. Disponível em http://rbqueimaduras.org.br. Acesso em 29 de outubro de 2013.

6. Macedo JLS, Santos JB. Complicações infecciosas em pacientes queimados. Rev. Soc. Bras. Cir. Plást. 2006; 21(2): 108-11. Disponível em 
http://www.rbcp.org.br/imageBank/PDF/21-02-08.pdf. Acesso em 05 de fevereiro de 2014.

7. Almeida JWF; Santos JN. Assistência de enfermagem em grupos de riscos a queimadura. Rev Bras Queimaduras. 2013; 12(2): 71-76. Disponível em http://rbqueimaduras.org.br. Acesso em 20 de junho de 2014.

8. Amaral MR, Martins DMFS, Souza RM, Menezes MHL, Matzenbacher CAW, Mendacolli TJ, Ribeiro FS, Muniz RK. Correção de retração cicatricial em mama por queimadura com uso de retalho de grande dorsal. Rev Bras Queimaduras. 2012;11(3):150-4. http://www.rbqueimaduras.com.br/detalhe_artigo.asp?id=122. Acesso em Acesso em 20 de junho de 2014.

9. Cunha AC; Mauro MYC. Educação continuada e a norma regulamentadora 32: utopia ou realidade na enfermagem? Rev. bras. Saúde ocup. 2010; 35 (122): 305313. Disponível em Disponível em http://wwww.scielo.br. Acesso em 18 de junho de 2014.

10. COFEN. Resolução - 358/2009. Brasília. 2009. Disponível em http://novo.portalcofen.gov.br/resoluo-cofen-3582009_4384.html. Acesso em 18 de junho de 2014.

11. Matos JC, Andrade FCB, Madeira MZA. Assistência de enfermagem a pacientes vítimas de queimaduras: uma revisão da literatura. Revista Interdisciplinar NOVAFAPI, Teresina. v.4, n.2, p.74-78, Abr-Mai-Jun. 2011. Disponível em http://www.uninovafapi.edu.br/sistemas/revistainterdisciplinar/pdf/revistavol4n2.pdf\#p age $=74$. Acesso em 05 de fevereiro de 2014 .

12. Minayo MCS. Pesquisa social: teoria, método e criatividade. 21.ed. Petrópolis/RJ: Vozes, 2009. 108 p.

13. Pastore E, Rosa LD, Homem ID. Relações de gênero e poder entre trabalhadores da área da saúde. Fazendo Gênero 8 - Corpo, Violência e Poder. Florianópolis. $2008 . \quad$ Disponível em: http://www.fazendogenero.ufsc.br/8/sts/ST25/Pastore-Rosa-Homem_25.pdf. Acesso em 24 de junho de 2014.

14. Silva, BA; Ribeiro, FA. Participação da equipe de enfermagem na assistência à dor do paciente queimado. Rev. dor, São Paulo, v. 12, n. 4, Dec. 2011. Disponível Revista Inova Saúde, Criciúma, vol. 7, n. 1, jul. 2018. ISSN 2317-2460 46 em: 
http://www.scielo.br/scielo.php?pid=S1806- 00132011000400011\&script=sci_arttext. Acesso em 25 de Junho de 2014.

15. Teixeira CC, Almeida WA. Sistematização da assistência de enfermagem ao paciente queimado. Universitári@ - Revista Científica do Unisalesiano - Lins - SP, ano 3, n.6, jan./jun./2012. Disponível em: http://www.salesianolins.br/universitaria/artigos/no6/artigo2.pdf. Acesso em 23 de junho de 2014.

16. Zanardo GM, Zanardo GM, Kaefer CT. Sistematização da Assistência de Enfermagem. Revista Contexto \& Saúde. Unijuí. Volume 10, n 20, jan/jun, 2011, pg 1371-1374.

Disponível

em

https://www.revistas.unijui.edu.br/index.php/contextoesaude/article/view/1811.

Acesso em 18 de junho de 2014.

17. Bolgiani A, Lima Jr EM, Serra MCV. Queimaduras: Conductas clínicas y quirúrgicas. São Paulo: Editora Atheneu, 2013.

18. Dornelas MT, Ferreira APR, Cazarim DB. Tratamento das queimaduras em áreas especiais. HU Revista, Juiz de Fora, v.35, n. 2, p. 119-126, abr./jun. 2009. Disponível em http://www.seer,ufjf.br. Acesso em 04 de dezembro de 2013.

19. Chaves SCS. Ações da enfermagem para reduzir os riscos de infecção em grande queimado no CTI. Rev Bras Queimaduras. 2013; 12(3): 140-4. Disponível em http://www.rbqueimaduras.com. Acesso em 24 de junho de 2014.

20. Franco D, Gonçalves LF. Feridas cutâneas: a escolha do curativo adequado. Rev Col Bras Cir. [periódico na Internet] 2008; 35(3). Disponível em http://www.scielo.br/scielo.php?pid=S0100-9912008000300013\&script=sci_arttext Acesso em 18 de junho de 2014.

21. Canela AF, Sória DAC, Barros FE, Melos ROL, Castro RC. Monitorização do paciente grande queimado e as implicações na assistência de enfermagem: relato de experiência. Rev Bras Queimaduras. 2011; 10 (4): 133-7. Disponível em http://wwww.scielo.br. Acesso em 24 de junho de 2014.

1Universidade do Extremo Sul Catarinense - UNESC - Avenida Universitária, 1105 Universitário - $\quad$ Criciúma/SC - $\quad$ CEP: 88806-000 amandaschardosim86@hotmail.com 
2Universidade do Extremo Sul Catarinense - UNESC - Avenida Universitária, 1105 Universitário - Criciúma/SC - CEP: 88806-000 - cida.oliveira2403@hotmail.com

3 Universidade do Extremo Sul Catarinense - UNESC - Avenida Universitária, 1105

- Universitário - Criciúma/SC - CEP: 88806-000 - karina@unesc.net

4 Universidade do Extremo Sul Catarinense - UNESC - Avenida Universitária, 1105

- Universitário - Criciúma/SC - CEP: 88806-000 - luk@unesc.net

5 Universidade do Extremo Sul Catarinense - UNESC - Avenida Universitária, 1105

- Universitário - Criciúma/SC - CEP: 88806-000 - mbz@unesc.net

Quadro 01: Características da equipe de Enfermagem.

Quadro 01: Características da equipe de Enfermagem.

\begin{tabular}{|c|c|c|c|c|c|c|}
\hline PROFISSIONAL & GENERO & IDADE & ESCOLARIDADE & $\begin{array}{l}\text { TEMPO DE } \\
\text { FORMAÇĀO }\end{array}$ & $\begin{array}{c}\text { TEMPO DE ATUAÇĀO } \\
\text { NA UNIDADE }\end{array}$ & CURSOS/CAPACITAÇŌES \\
\hline E1 & Feminino & 42 & Superior Completo & 12 anos & $3 a n 05$ & Cardiologia e administração hospitalar \\
\hline E2 & Feminino & 56 & Superior Completo & 27 anos & 11 anos & $\begin{array}{l}\text { Administração serviços de enfermagem e } \\
\text { fitoterapia }\end{array}$ \\
\hline TE1 & Feminino & 48 & Ens. Médio Completo & 12 anos & 9anos & Não \\
\hline TE2 & Feminino & 37 & Superior Incompleto & 16 anos & 7anos & Instrumentaçâo Cirúrgica \\
\hline TE3 & Feminino & 52 & Ens. Médio Completo & 24 anos & 24 anos & Não \\
\hline TE4 & Feminino & 61 & Ens. Médio Completo & 34 anos & 28 anos & Não \\
\hline TE5 & Feminino & 62 & Ens. Médio Completo & 16 anos & 16 anos & Não \\
\hline TE6 & Feminino & 53 & Ens. Médio Completo & 20 anos & 12 anos & Enfermagem UTl e Neonatal \\
\hline TE7 & Feminino & 39 & Ens. Médio Completo & 14 anos & 9anos & Não \\
\hline TE8 & Feminino & 36 & Superior Incompleto & 14 anos & 1 ano e 6 meses & Não \\
\hline TE9 & Feminino & 39 & Superior Incompleto & 9 anos & 9anos & Não \\
\hline TE10 & Feminino & 37 & Superior Incompleto & 15 anos & 8 anos & Não \\
\hline TE11 & Feminino & 40 & Superior Completo & 15 anos & 10 anos & $\begin{array}{l}\text { Enfermagem do trabalho e Gestão em } \\
\text { desastres }\end{array}$ \\
\hline TE12 & Feminino & 43 & Ens. Médio Completo & 20 anos & 8 anos & Não \\
\hline TE13 & Feminino & 57 & Ens. Médio Completo & 25 anos & 25 anos & Năo \\
\hline
\end{tabular}

Fonte: Dados da pesquisa, 2014.

Figura 01: Retração e deformidade em pós-queimadura.

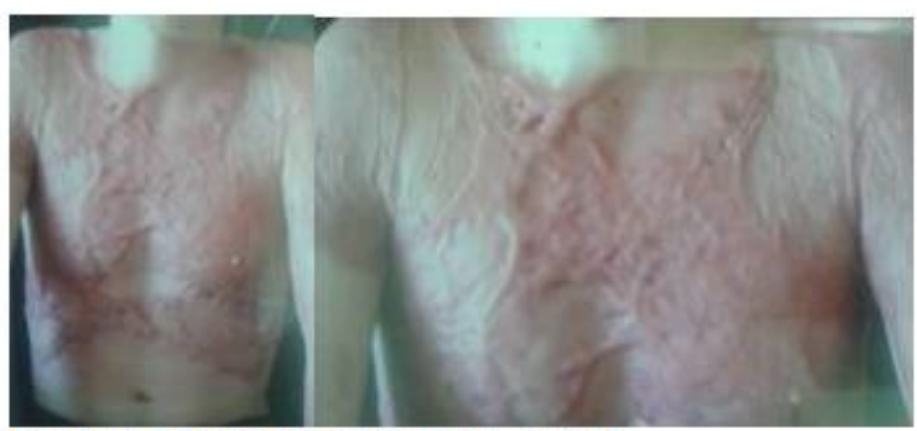

Fonte: Dados da Pesquisa, 2014. 